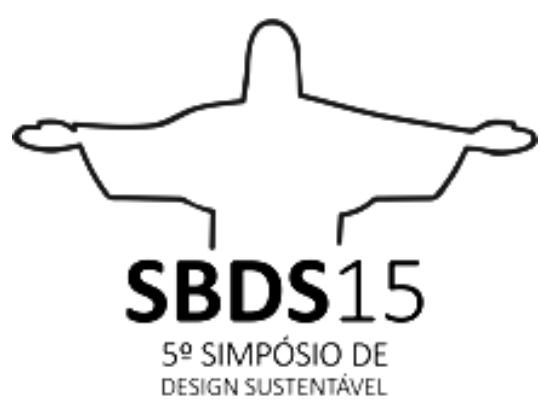

Rio de Janeiro, 11 de novembro a 13 de novembro de 2015

\title{
CADEIRA CAMALEÃO
}

inovação para a sustentabilidade no segmento de food service

\author{
Priscilla Ramalho Lepre \\ Universidade Federal de Alagoas \\ cillaramalho@yahoo.com.br \\ Thais Vieira \\ Universidade Federal do Rio de Janeiro \\ contato@thaisvieira.com.br
}

Resumo: Este artigo apresenta resultados parciais do Projeto Design Seguro, que tratam do design de uma cadeira intrinsecamente sustentável e das inovações que promoveram a extensão do ciclo de vida.

Palavras-chave: Design para a sustentabilidade, cadeira, design do ciclo de vida, food service

Abstract: This article presents partial results of the Project Design Seguro, dealing with the design of an intrinsically sustainable chair and innovations that promoted the extension of the life cycle.

Keywords: Design for sustainability, chair, life cycle design, food service

\section{INTRODUÇÃO}

Em estabelecimentos de food service - aqueles dedicados à alimentação fora do lar, como bares e restaurantes, o 'ambiente', com todos os seus elementos estéticos, é fator importante na experiência do usuário. Mobiliário, cores, texturas e iluminação, devem unir-se de forma harmônica à aromas e sabores, compondo o complexo contexto do alimentar-se. 
Este setor costuma seguir a moda, que dita temas, estabelece padrões e gera necessidade renovar periodicamente a 'decoração' para fidelizar clientes e conquistar novos. Para isto os estabelecimentos costumam desfazer-se de peças de mobiliário ainda em plenas condições de uso, em prol de 'renovar o visual'.

Esta disposição de móveis íntegros por motivação puramente estética gera produção e consumo desnecessários de novos produtos, o que impacta o ambiente de maneira negativa. Em busca soluções alternativas a esta questão, realizou-se o Projeto de Pesquisa e Desenvolvimento Design Seguro, entre os anos de 2009 e 2011, que, além de propor soluções de segurança nos estabelecimentos de food service através do mobiliário, contemplou a geração de mobiliário intrinsecamente sustentável.

Este artigo aborda um dos resultados finais do Projeto Design Seguro, que trata da ampliação do ciclo de vida de um dos produtos resultantes: a Cadeira Camaleão, através do sistema de troca de espaldares, que propõe estender o período de uso do produto em até cinco vezes.

Por Ciclo de Vida do Produto entende-se "o período que comporta desde a extração dos recursos necessários para a produção dos materiais que o compõe até o último tratamento destes mesmos materiais após o uso do produto." (MANZINI; VEZZOLI; 2005). São fases do ciclo de vida do produto: pré-produção, produção, distribuição, uso e descarte.

Isso posto, são apresentados na sequência: o projeto e o método de pesquisa, o estudo de caso e as conclusões.

\section{VISÃO GERAL DO MÉTODO}

O Projeto Design Seguro resultou da parceria entre o SENAI-PR, o Conselho Nacional de Desenvolvimento Científico e Tecnológico- CNPq, a Universidade Federal do Paraná, através do Núcleo de Design Sustentável- NDS/UFPR, a Polícia Militar do Paraná-PM/PR e a Movelaria Paranista, contemplando o Edital SENAI/SESI de Inovação 2009 -n. 555959/2009-0.

O escopo principal do projeto tratou da criação e desenvolvimento de soluções em design de mobiliário que, empregando os fundamentos do design contra o crime e do design para a sustentabilidade, contribuíssem para a redução de furtos no interior de espaços gastronômicos (eventos, bares, casas noturnas e meios de hospedagens), bem como para a segurança dos próprios produtos, promovendo a garantia ou extensão do seu ciclo de vida.

Visto que os saberes necessários ao seu desenvolvimento são recentes ou em processo de construção, esta pesquisa foi caracterizada como Exploratória. O Método principal de pesquisa empregado foi o Estudo de Caso, por se tratar de problemática 
atual, com pouco ou nenhum controle das variáveis e por responder pergunta do tipo 'como' (YIN, 2005).

De forma a subsidiar o Estudo de Caso, foram necessárias etapas precedentes sendo a primeira, uma Pesquisa Bibliográfica e a segunda uma Survey, conforme mostra a Figura 1 a seguir:

\section{Visão Geral do Método | Design Seguro}

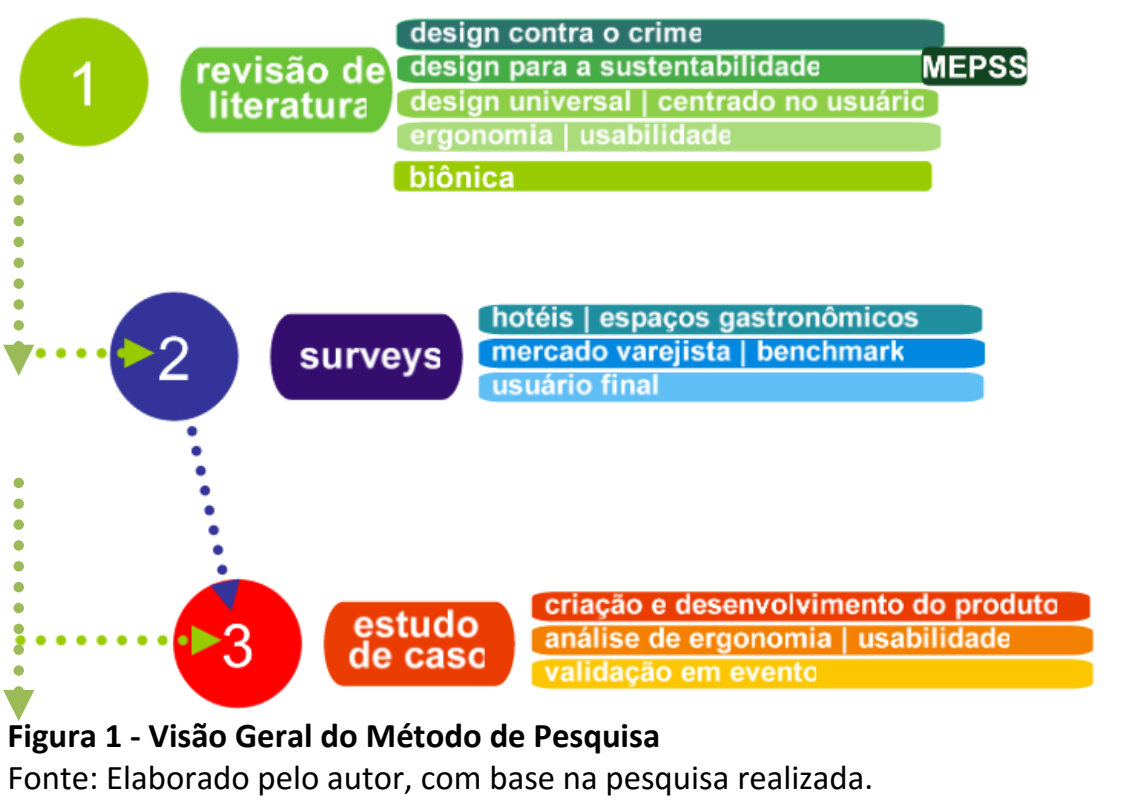

Segundo descrito na Figura 1, a revisão de literatura contou com pesquisas em Design Contra o Crime, Design para a Sustentabilidade, Design Centrado no Usuário, Ergonomia/Usabilidade e Biônica. As surveys, no número de duas, deram conta do estado da arte, tanto em relação à furtos no interior de estabelecimentos de food services, quanto ao design para a sustentabilidade, na perspectiva dos proprietários e de usuários.

Para a realização do estudo de caso, foram criados, desenvolvidos e executados 20 (vinte) produtos, incorporando soluções de design contra o crime e design para a sustentabilidade, concomitante ou separadamente. Como o presente artigo trata apenas dos aspectos da sustentabilidade de um dos produtos, a Cadeira Camaleão e do sistema de produto-serviço que esta compõe, na próxima sessão serão apresentados dados relevantes ao desenvolvimento da mesma, em detrimentos dos demais.

\section{ESTUDO DE CASO: CADEIRA CAMALEÃO E O SISTEMA 7 VIDAS}

\subsection{Caracterização do Estudo e Coleta de Dados}

O estudo de caso deu-se na empresa Movelaria Paranista, situada na cidade de Curitiba, Paraná. No mercado desde 1992, atou na confecção de móveis residenciais sob medida durante 17 anos. Em 2009, com a possibilidade de se reinserir no mercado 
moveleiro em um novo segmento, o de móveis comerciais, a empresa participou da seleção de projetos para Edital SESI-SENAI DE INOVAÇÃO, sendo contemplada.

Dentro dos objetivos específicos do projeto estava a criação e desenvolvimento de produtos mobiliários que apresentassem em seu design soluções para a redução do furto no interior de espaços gastronômicos e de meios de diversão. As questões da sustentabilidade deveriam ser abordadas desde a pré-produção, gerando produtos intrinsecamente sustentáveis.

Por parceiros, além do Senai-PR, que forneceu a estrutura física e profissionais de design, a empresa contou com dois pesquisadores financiados pelo CNPq, sendo um mestre e um bacharel em Design. Contou também com a parceria do Núcleo de Design e Sustentabilidade da UFPR e seu knowhow no desenvolvimento de soluções sustentáveis e da Polícia Militar do Paraná, através de consultorias sobre teoria dos delitos e soluções de segurança.

Desta forma, o projeto, com duração de 02 anos, teve início com a apresentação de plano de trabalho que propunha a criação, o desenvolvimento e prototipação de produtos no período de 12 meses e seu lançamento no mercado em feira nacional do ramo de equipamentos para food service. Os meses restantes seriam empregados na validação das soluções, redesign dos produtos e implementação do sistema de produto-serviço.

O desenvolvimento do projeto respeitou as etapas propostas pela Metodologia para o Desenvolvimento de Sistema de Produto-Serviço - MEPSS (VEZZOLI, 2010), sendo elas:

- Análise estratégica;

- Exploração de oportunidades;

- Desenvolvimento de conceitos;

- Detalhamento de sistemas (produto);

- Comunicação.

Para as fases de análise estratégica e exploração de oportunidades realizou-se pesquisa bibliográfica nas áreas de Segurança, Design Contra o Crime, Design para a Sustentabilidade, Mobiliário e Food Service. Além disto, foi feita ampla pesquisa imagética junto aos concorrentes, a partir da qual foram desenvolvidos painéis similares, semânticos, sincrônicos e painéis de tendências.

Concomitantemente, foram realizadas duas Surveys: uma nos estabelecimentos comerciais (S1-food service) e outra junto aos seus frequentadores (S2-usuários finais), com o objetivo de mapear as várias faces do mercado consumidor. Neste artigo são apresentados os principais resultado relativos a S1, realizada em 20 (vinte) estabelecimentos e que levaram a definição do produto Cadeira Camaleão.

A amostra de estabelecimentos foi composta de 08 restaurantes, 04 bares, 02 meios de hospedagem, 05 locais para evento e 01 casa noturna, com capacidade de atendimento variando entre 102 e 4000 pessoas e com ticket mínimo entre $R \$ 9,00$ 
(nove reais) e $\mathrm{R} \$ 500.000,00$ (quinhentos mil reais). A entrevista contou com questões sobre o histórico do local, estrutura física, mobiliário, orientações estéticas, público frequentador e segurança. Como principais dados relativos ao mobiliário, que orientaram a fase posterior, estão:

- O período médio de troca de 'decoração', com troca parcial ou total do equipamento mobiliário é de 05 anos;

- As principais motivações para as trocas são: depreciação estética, perda da funcionalidade;

- As características do mobiliário observadas no momento da compra e passíveis de serem desenvolvidas e melhoradas através da aplicação das diretrizes do design para a sustentabilidade são:

- Durabilidade;

- Confiabilidade;

- Materiais;

- Facilidade de manutenção e limpeza.

- Serviços agregados aos produtos são considerados como diferencial para $83,33 \%$ dos entrevistados.

Analisando todos os dados levantados, pôde-se verificar, dentre outras, a oportunidade para a criação de novos produtos que, sendo adaptáveis às questões estéticas e passível de manutenção da funcionalidade, tivessem seu período de uso ampliado para além de 5 anos. Também vislumbrou-se a possibilidade de inserção de sistema de produto+serviço voltado ao setor de food service.

Através da revisão de literatura, destacou-se as diretrizes e requisitos do Design para a Sustentabilidade - D4S e do Design do Ciclo de Vida do Produto - LCD (Life Cycle Design), conforme proposto por Manzini e Vezzoli (2005):

- Minimização de recursos - reduzir materiais e energia;

- Escolha de produtos e processos de baixo impacto - selecionar materiais, processos e fontes energéticas de baixo impacto e maior ecocompatibilidade;

- Otimização da vida dos produtos - projetar artefatos que perdurem;

- Extensão da vida dos materiais - projetar em função da valorização e reaplicação dos materiais descartados;

- Facilidade de desmontagem - projetar em função da facilidade da separação das partes e dos materiais.

Para produtos do tipo mobiliário, "bens duráveis de longa duração" (GORINI, 1998) e cujo período de uso não requer trocas materiais e energéticas, a estratégia mais eficaz, segundo LEPRE (2008) é a otimização da vida do produto, promovendo sua durabilidade e integridade. De forma a contribuir para isto, foram selecionadas estratégias para extensão do ciclo de vida do mobiliário, propostas por Chaves (2007), a serem empregadas no design dos produtos. As mais importantes foram:

Extensão do CV- Uso: Durabilidade

- Projetar a durabilidade de todos os componente;

- Projetar a durabilidade da vida útil de componentes que serão trocados durante o ciclo de vida do produto, correspondente a sua duração prevista;

- Selecionar materiais duráveis considerando às necessidades a vida útil do produto;

- Evitar materiais permanentes para funções temporárias;

- Extensão da durabilidade do produto através de troca de componentes; 
- Projetar encaixes com fácil retirada para evitar danos;

- Usar materiais de acordo com suas funções;

\section{Extensão do CV- Uso: Adaptabilidade}

- Facilitar o "upgrade"

- Facilitar a substituição de componentes facilmente danificáveis;

- Projetar produtos readaptáveis ou multifuncionais para adaptação e respeito as evoluções físicas e culturais;

- Projetar móveis adaptados às necessidades estéticas dos consumidores;

- Flexibilizar o uso do mobiliário;

- Fazer móveis que durem;

- Projetar móveis compatíveis com adaptações funcionais e estéticas;

- Projetar para que as partes necessárias ao upgrade possam ser encontradas no comércio;

- Projetar para a confiabilidade;

- Diminuir o número de peças e componentes;

- Simplificar o produto (sem comprometer a durabilidade);

- Evitar o uso de pregos;

- Usar materiais de qualidade.

Extensão do CV- Uso: Re-Uso

- Facilitar o acesso e remoção de partes para re-uso;

- Projetar partes modulares para intercâmbio;

- Projetar partes padronizadas;

- Melhorar a resistência de partes frágeis;

Entre as estratégias acima apresentadas, em observância às oportunidades mostradas pela pesquisa de campo, destacam-se aquelas que tangem à adaptabilidade do produto durante o período de uso, como forma de estender seu ciclo de vida melhorando sua performance funcional e estética. Isto posto, deu-se início à criação do conceito e ao período de desenvolvimento e prototipagem, cujo resultados são descritos a seguir.

\subsection{Projeto de Produto Intrinsecamente Sustentável - Cadeira Camaleão}

Conforme exposto anteriormente, apesar do Projeto Design Seguro abranger a criação de 20 produtos, este artigo trata apenas de um deles, a Cadeira Camaleão, que de acordo com texto anterior, foi norteada pelas diretrizes e estratégias do Design para a Sustentabilidade-D4S e do Life Cycle Design- LCD.

Foram observadas e aplicadas estratégias para todas as fases do ciclo de vida. No período de pré-produção, foram selecionados os insumos e processos visando atender às diretrizes da sustentabilidade juntamente com as principais questões relativas ao período de uso, objetivando a durabilidade do produto. Desta forma, para a estrutura do produto optou-se pela madeira de eucalipto e entrada da empresa na cadeia de custódia do Selo FSC - Forest Stewardship Council. Assim, a estrutura foi desenvolvida $100 \%$ em madeira maciça de reflorestamento e as aparas do processo produtivo foram utilizadas na confecção do assento, reduzindo o desperdício em $80 \%$ e dispensando, assim, o uso do MDF (Médium Density Fiberboard).

Para a composição do assento optou-se pelo uso de placa de espuma $67 \%$ reciclada pré-consumo, ou seja, formada por resíduos de aparas resultantes do processo produtivo e reaglutinadas por calor. Uma vantagem desta placa é a densidade adequada à sustentação do peso corporal humano. Outra é que com o processo de reaglutinação dos fragmentos de espuma, tem-se uma superfície com veios 'emborrachados' que criam atrito com a superfície em contato, mantendo-a no 
lugar e eliminando a necessidade de colagem da espuma no assento/espaldar. Este procedimento reduz etapas de fabricação e facilita a desmontagem para manutenções, reuso e recuperação energética.

Durante a produção, para a união das partes estruturais, optou-se pelo emprego de encaixes e cavilhas com cola de alta durabilidade e livre de PVC. Estas escolhas contribuem para a garantia da integridade do período de uso, para separação de partes, ação necessária para manutenção e para a recuperação energética ao fim do ciclo de vida.

A Figura 2 a seguir apresenta detalhe do produto, resumindo as escolhas assertivas na fase de pré-produção e de produção.
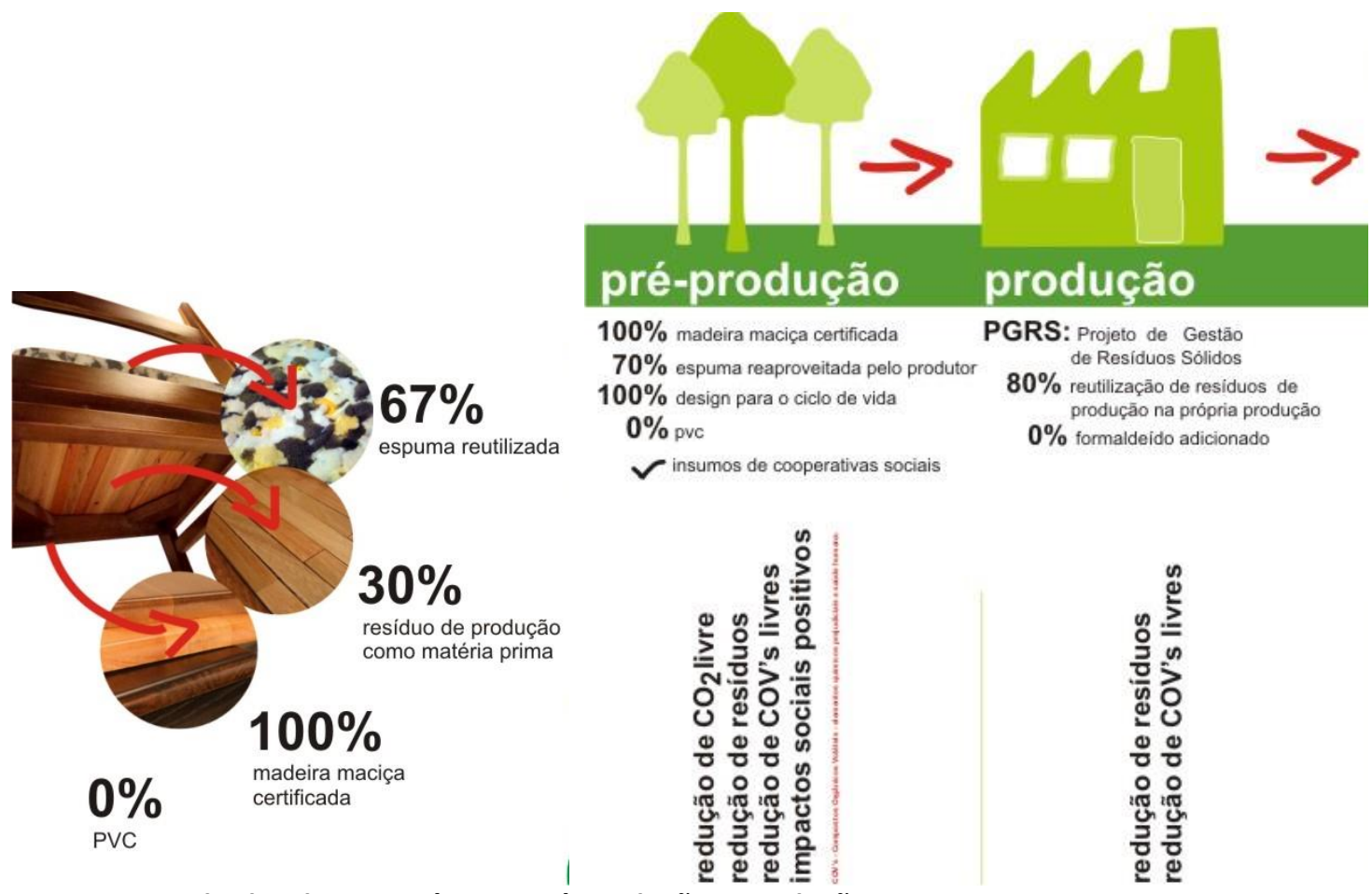

Figura 2 - Resultados das Estratégias - Pré-Produção e Produção Fonte: Elaborado pelo autor, com base na pesquisa realizada.

Entre as opções de acabamento, foram desenvolvidas capas para espaldares utilizando resíduos de tecidos da indústria moveleira, realizadas pelos membros da Cooperativa Zumbi dos Palmares, situada na favela Zumbi, periferia de Curitiba. Com isso a empresa criou oportunidades de trabalho e geração de renda para a comunidade.

Para otimizar a distribuição do produto foi desenvolvida uma embalagem em papelão que permite a acomodação de 04 cadeiras, reduzindo em $37 \%$ a área de papelão utilizada, eliminando o uso de plástico e permitindo o transporte de maior quantidade de produtos contemporaneamente. Esta estratégia reduziu em 57,24\% o CO2 liberado pela queima de óleo diesel. Para o período de uso foram consideradas as necessidades específicas do setor A Figura 3, a seguir, resume as estratégias empregadas em cada fase do ciclo de vida do produto: 


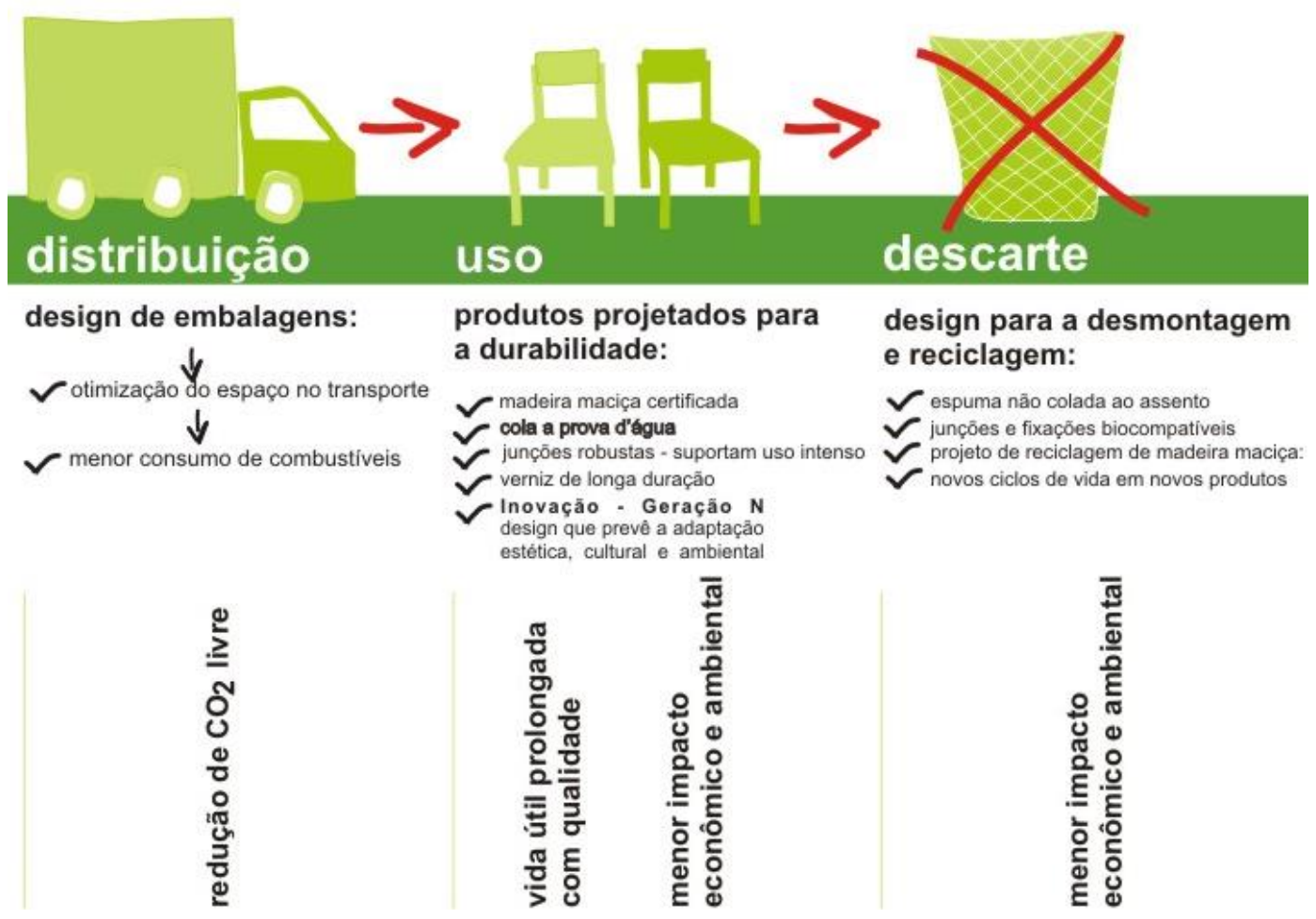

Figura 3 - Estratégias Empregadas no Ciclo de Vida da Cadeira Camaleão

Fonte: Elaborado pelo autor, com base na pesquisa realizada.

Como mostra a figura anterior, além das estratégias utilizadas nas fases de préprodução, produção e distribuição, para caracterizar a cadeira Camaleão como um produto intrinsecamente sustentável, também a fase de uso foi contemplada com soluções sustentáveis, consideradas inovadoras para o setor de equipamento para food service, apresentadas na sessão seguinte.

\subsection{Inovação para a Extensão do Ciclo de Vida do Produto}

Durante a Survey junto aos estabelecimentos de food service, pode-se observar que a necessidade de adequação estética periódica era temática recorrente. Esta passa por pinturas de paredes, trocas de elementos decorativos e por fim, pela troca dos equipamentos móveis. Conforme relatado as trocas são feitas, em média, a cada 05 anos. Com a análise dos dados e imagens coletados, pôde-se verificar que, em sua maioria, os móveis estavam íntegros no momento em os proprietários já apontavam a necessidade de troca, bem como exercendo plenamente as funções para o quais foram projetados.

Durante as visitas de campo observou-se um comportamento comum nestes estabelecimentos, quando consideravam a necessidade de modificação estética: o uso de capas de tecido para cobrir as cadeiras. Questionados sobre esta prática, os respondentes colocaram que estas coberturas contribuíam para a diferenciação 'visual' do recinto, dando à possibilidade do uso de novas cores e texturas.

Analisando as imagens, verificou-se que a parte mais 'visível' na composição do ambientes eram os espaldares das cadeiras, tanto de costas, como acima da linha das mesas. Apresentava-se aí uma oportunidade para inovação. Desta forma, combinando 
estes dados, propôs-se que a cadeira tivesse "espaldares cambiáveis", promovendo concomitantemente a adequação estética dos estabelecimentos extensão do período de uso do produto, evitando a troca. Nascia assim, a Cadeira Camaleão, que, conforme a Movelaria Paranista (2015) "muda de pele de acordo com a decoração".

Para tanto foi desenvolvida uma estrutura simples, baseada em encaixe e parafuso, que permite ao usuário com apenas um movimento retirar e com outro recolocar o espaldar na estrutura (FIGURA 4).

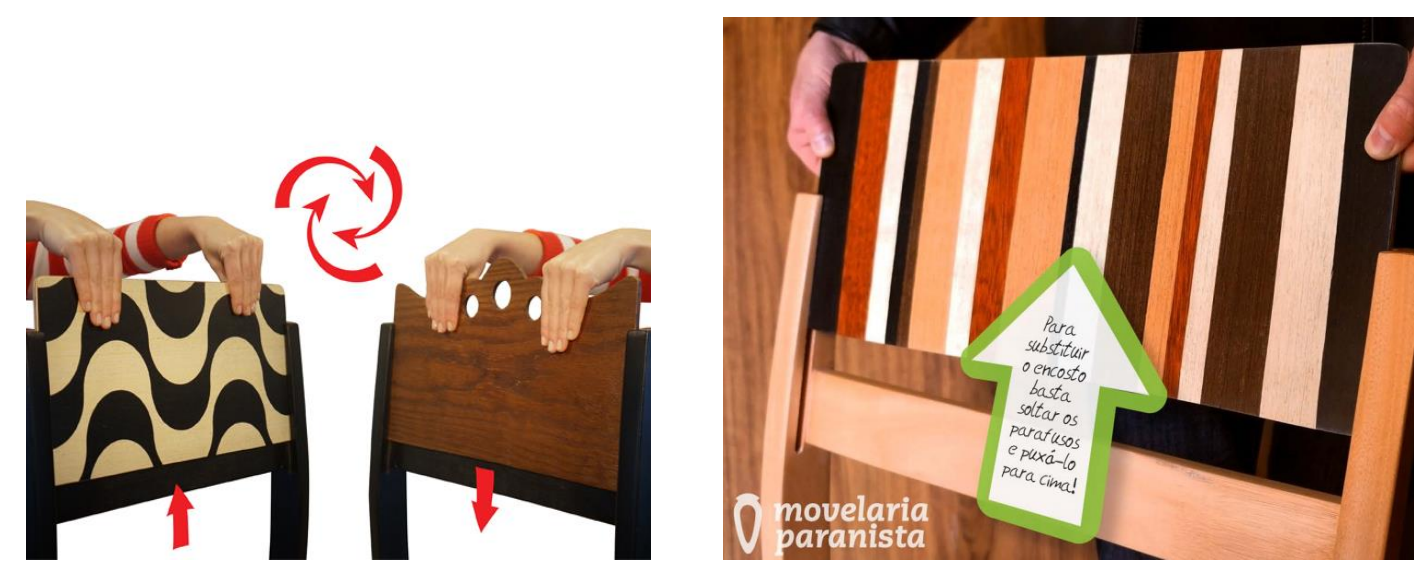

Figura 4 - Cadeira Camaleão - troca de espaldares

Fonte: Movelaria Paranista. Disponível em: www.movelariaparanista.com.br

Esta solução permite a adequação estética eliminando o problema que levava ao fim prematuro do ciclo de vida do produto ainda íntegro. Através do design, propôs-se também a criação de diversos modelos de espaldares e a customização dos elementos, conforme mostra a Figura 5 . Ao invés de uma cadeira, do ponto de vista do cliente, o estabelecimento passa a ter várias.

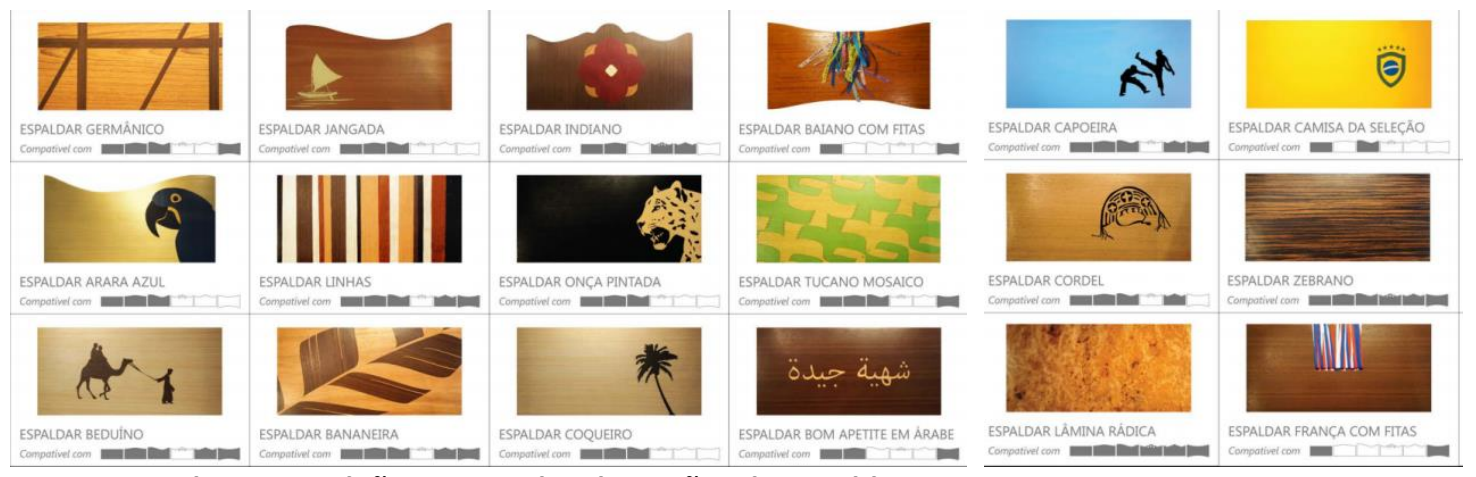

Figura 5 - Cadeira Camaleão - exemplos de opções de espaldares

Fonte: Movelaria Paranista. Disponível em: www.movelariaparanista.com.br

Como sistema de produto+serviço foi criada uma 'bolsa de espaldares' que possibilita aos clientes a troca do elemento com devolução do anterior. Este passa pelas devidas manutenções e fica disponível para vendas posteriores (com redução de custo), recebendo um selo compatível com o número de reusos. Desta forma evita-se novas manufaturas e descartes. Isto posto, tem-se a ampliação do ciclo de vida e a valorização de seus materiais, como pode ser visto na Figura 6. 


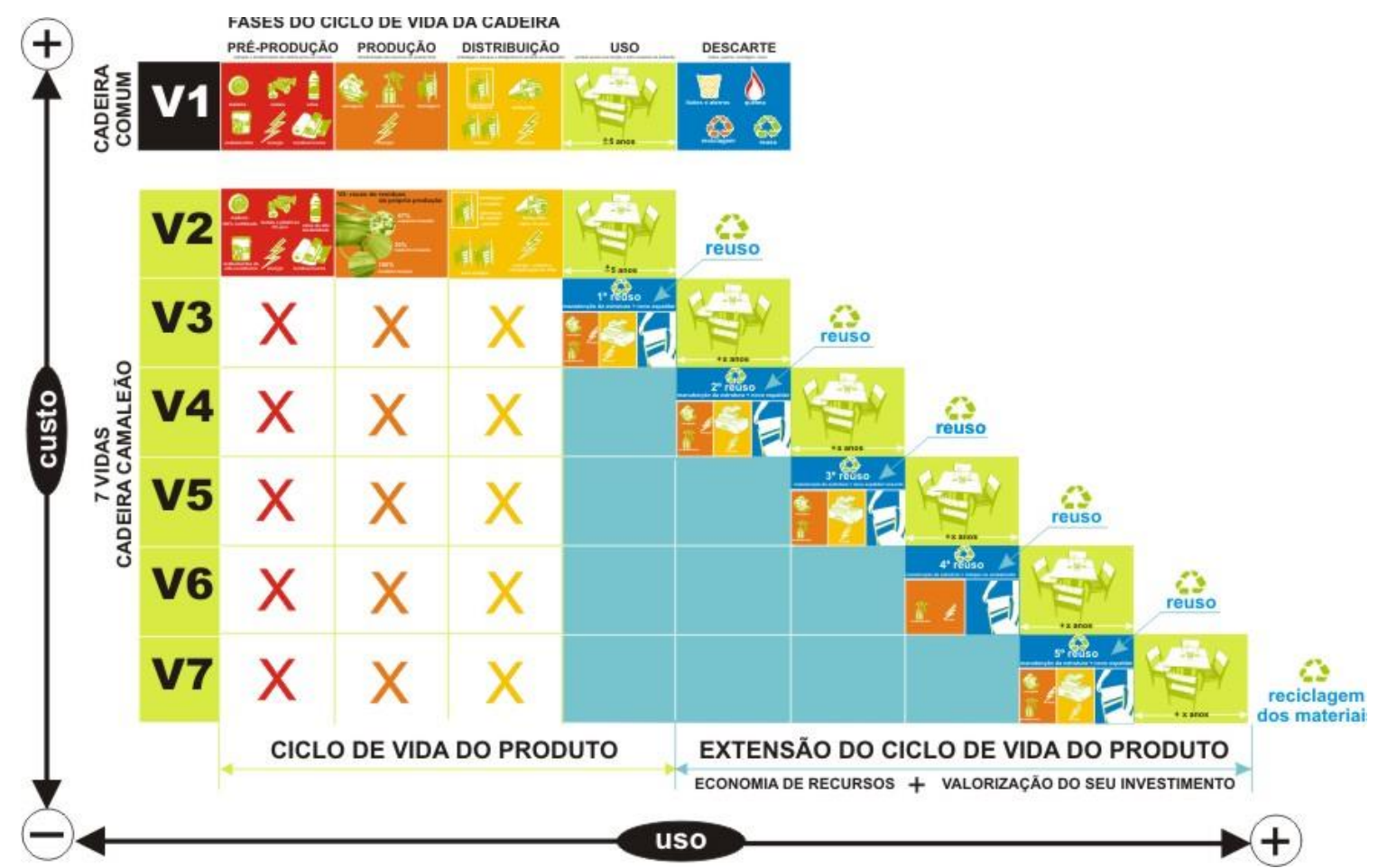

Figura 6 - Cadeira Camaleão - Extensão do Ciclo de Vida

Fonte: Elaborado pelo autor, com base na pesquisa realizada.

A figura acima faz a comparação entre as cadeiras comuns utilizadas como equipamentos de food service e a Cadeira Camaleão. Nota-se que o ciclo de vida das cadeiras comuns termina ao final de 05 anos, conforme dados apresentados. Com o design da Cadeira Camaleão, este período pode ser ampliado em 5 vezes, ou seja, a cadeira passa a durar 25 anos em uso. Isto é possível através da troca de espaldares, que mantém a estrutura íntegra e atende aos requisitos de adequação estética dos consumidores, com as manutenções necessárias e devidos cuidados. Com esta solução elimina-se novos processos produtivos completos, reduzindo os impactos sobre os recursos materiais e energéticos.

Entre outras vantagens, o design da Cadeira Camaleão possibilita a fidelização do cliente através do uso dos citados serviços de customização e reparos de espaldares e do produto completo, garantindo assim a otimização do seu uso e concretização da expansão do seu ciclo de vida.

Como resultados do Projeto, após a conclusão do Projeto e da mudança de processo de produção artesanal para a escala industrial a empresa teve um crescimento de $100 \%$ no faturamento e de $300 \%$ em equipamento deixando sua sede em prol de maior espaço. A Movelaria Paranista concretizou sua participação no mercado, tendo como 'carro chefe' a Cadeira Camaleão. Recebeu o Prêmio Ozires Silva de Empreendedorismo Sustentável e medalha de Bronze na fase brasileira do Prêmio IF de Design, expondo seus produtos em espaços como o Museu Oscar Niemeyer e terceiro lugar na Mostra Senai Design.

\section{CONCLUSÃO}


Este artigo apresentou resultados parciais finais do Projeto Design Seguro, que dizem respeito a criação da Cadeira Camaleão, produto intrinsecamente sustentável, utilizada como equipamentos no segmento de food service brasileiro.

Durante o texto pode-se verificar que este tipo de produto é necessário na busca de uma sociedade mais sustentável. Soluções para a otimização e ampliação do período de uso de produtos de longa duração, além de atenderem as questões ambientais, tornam-se estratégias de negócio, pois produtos sustentáveis podem, ao longo do tempo representar economia para seus compradores e apresentam grande demanda no mercado.

Para incentivar e potencializar soluções inovadoras deve-se criar parcerias entre governo, iniciativa privada e academia. Desta forma, editais de fomento, como o que contemplou este projeto, devem ser uma constância, de forma a apoiar o desenvolvimento destas empresas e promover a geração de novos empregos e crescimento sustentável do país.

\section{REFERÊNCIAS}

CHAVES, Liliane Iten. Design for Environmental Sustainability: design strategies, methods and tools for the furniture sector. 2007. Tese - Istituto Politecnico di Milano, Dipartamento di Design e Comunicazione Mediale.

GORINI, A.P.F. Panorama do setor moveleiro no Brasil, com ênfase na competitividade externa a partir do desenvolvimento da cadeia industrial de produtos sólidos de madeira. Rio de Janeiro: BNDES, 1998.

LEPRE, Priscilla Ramalho. Diretrizes para Aplicação de Dispositivos Poka-Yoke no Design De Mobiliário: Uma Estratégia para o Design Sustentável. 2008. Dissertação - Universidade Federal do Paraná.

MANZINI, Ezio; VEZZOLI, Carlo. O Desenvolvimento de Produtos Sustentáveis: Os Requisitos Ambientais dos Produtos Industriais. São Paulo: EDUSP, 2005.

MOVELARIA PARANISTA. Cadeira Camaleão. Curitiba, 2015. Disponível na internet por http em: http://www.movelariaparanista.com.br

VEZZOLI, Carlo. Design de Sistemas para a Sustentabilidade. Salvador: EDUFBA, 2010. 